\title{
Expired Podocip drug as potential corrosion inhibitor for carbon steel in acid chloride solution ${ }^{1}$
}

\author{
P. Dohare, ${ }^{\mathrm{a} *}$ D.S. Chauhan ${ }^{\mathrm{a}, \mathrm{b}}$ and M.A. Quraishi ${ }^{\mathrm{c}}$ \\ ${ }^{a}$ Department of Chemistry, Indian Institute of Technology, Banaras Hindu University, \\ Varanasi 221005, India \\ ${ }^{b}$ Present Address: C-8, Ashokpuram, Dafi, Varanasi-221011, India \\ ${ }^{c}$ Center of Research Excellence in Corrosion, Research Institute, King Fahd University \\ of Petroleum and Minerals, Dhahran 31261, Saudi Arabia \\ *E-mail: paruldohare.17@gmail.com
}

\begin{abstract}
The application of expired drugs as corrosion inhibitors provides a cost effective and environmentally benign alternative to otherwise tedious and costly disposal/degradation process. In this context, we have investigated the use of expired Podocip (PCIP) drug as corrosion inhibitor for carbon steel in $1 \mathrm{M} \mathrm{HCl}$ by weight loss and electrochemical methods. Polarization curves revealed that the inhibiting action of the PCIP is mixed-type. The adsorption of PCIP on carbon steel surface obeys the Langmuir isotherm. Impedance analysis showed that the presence of inhibitor considerably affects the charge transfer resistance and the double layer capacitance of carbon steel surface. SEM and AFM studies evidenced the formation of a protective film over metal surface.
\end{abstract}

Keywords: Podocip; carbon steel; electrochemical analysis; adsorption.

Received: November 30, 2017. Published: December 25, 2017

doi: $\underline{10.17675 / 2305-6894-2018-7-1-3}$

\section{Introduction}

Carbon steel is extensively used in a number of industries owing to its cost effectiveness and excellent mechanical strength. Industrial processes use mineral acids such as hydrochloric and sulphuric acids for acid pickling and acid descaling etc. to improve oil recovery and removal of scales and salt deposits [1-3]. These acids cause severe corrosion of the oil well/pipe or such structures made up of carbon steel [4-7]. To prevent this corrosive attack, the use of organic inhibitors is one of the most prominent methods $[8,9]$. These organic inhibitors have hetero atoms like oxygen, nitrogen, sulphur, phosphorus. Universally it is reported that $\mathrm{N}$-containing organic inhibitors behave as valuable corrosion inhibitors for carbon steel in acidic solution. The adsorption of inhibitors on carbon steel surface, takes place via formation of co-ordinate covalent bonds (chemical adsorption), or

\footnotetext{
${ }^{1}$ Note from the Editors: The authors's opinion that the degree of surface coverage by an inhibitor can be calculated from mass loss data for compounds that affect the activation energy of corrosion is deemed not quite valid by the Editors, as explained in detail in Int. J. Corros. Scale Inhib., 2015, 4, no. 2, 108.
} 
by electrostatic interaction between metal surface and inhibitor molecule (physical adsorption) [10-13].

A large number of organic compounds have been studied as corrosion inhibitors. However, unfortunately most of the organic inhibitors used are very expensive and pose health hazards. Thus; it remains an important objective to search for cost-effective and non-hazardous inhibitors for the protection of metals against corrosion. In this connection, the influence of nontoxic organic compounds and drugs on the corrosion of metals in acid media was investigated by several authors. Among organic corrosion inhibitors, drugs constitute one of the most sought after types owing to their non-toxicity and environmentally benign nature. Most of the drugs are large organic molecules that contain above structural characteristics in abundance and hence meet the criteria of good corrosion inhibitors. Therefore, the application of drugs as corrosion inhibitors, in recent years, has become one of the most actively investigated topics [14-18].

We herein, for the first time report the application of expired drug PCIP as corrosion inhibitor for mild steel in $1 \mathrm{M} \mathrm{HCl}$ solution. The present study was undertaken to probe the corrosion inhibition of carbon steel in $1 \mathrm{M} \mathrm{HCl}$ by expired Podocip (PCIP). The study was carried out by potentiodynamic polarization, EIS, weight loss, SEM and AFM analyses.

\section{Experimental}

\subsection{Materials and sample preparation}

Podocip, (PCIP) a trade name of Cefpodoxime Proxetil, is an orally administered, extended spectrum, semi-synthetic antibiotic of the cephalosporin class. The chemical name is $(R S)$ 1-(isopropoxycarbonyloxy)ethyl $(+)-(6 R, 7 R)-7-[2-(2$-amino-4-thiazolyl)-2- $\{(Z)$ methoxyimino $\}$ acetamido]-3-methoxymethyl-8-oxo-5-thia-1-azabicyclo[4.2.0]oct-2-ene-2-carboxylate. Its empirical formula is $\mathrm{C}_{21} \mathrm{H}_{27} \mathrm{~N}_{5} \mathrm{O}_{9} \mathrm{~S}_{2}$ and its structural formula is represented below. Corrosion tests were performed on carbon steel strips having following dimensions: $2.5 \times 2 \times 0.025 \mathrm{~cm}$ containing $(\mathrm{wt} \%): \mathrm{C}=0.076, \mathrm{Mn}=0.192, \mathrm{P}=0.012, \mathrm{Si}=0.026, \mathrm{Cr}=$ $0.050, \mathrm{Al}=0.023$ and balance $\mathrm{Fe}$. The strips were polished with emery papers of grade $600,800,1000$ and 1200 respectively to mirror finish, degreased with acetone and finally dried at ambient temperature. They were subsequently used for weight loss and surface examination studies.

\subsection{Gravimetric measurement}

Gravimetric experiments were performed according to the standard method [19, 20]. The corrosion rates $C_{\mathrm{R}}\left(\mathrm{mg} \mathrm{cm}^{-2} \mathrm{~h}^{-1}\right)$ were calculated from the following equation [20]:

$$
C_{\mathrm{R}}=\frac{W}{A t}
$$


where $W$ is the average weight loss of a carbon steel strip, $A$ the total area of a carbon steel strip and $t$ is immersion time $(3 \mathrm{~h})$. With the calculated corrosion rate, the inhibition efficiency $\eta \%$ was calculated as follows [21]:

$$
\eta \%=\frac{C_{\mathrm{R}}-C_{\mathrm{R}(\mathrm{i})}}{C_{\mathrm{R}}} \times 100
$$

and surface coverage $(\theta)$ values were calculated by Equation 3:

$$
\theta=\frac{C_{\mathrm{R}}-C_{\mathrm{R}(\mathrm{i})}}{C_{\mathrm{R}}}
$$

where $C_{\mathrm{R}}$ and $C_{\mathrm{R}(\mathrm{i})}$ are the values of the corrosion rates $\left(\mathrm{mg} \mathrm{cm}^{-2} \mathrm{~h}^{-1}\right)$ of carbon steel in the absence and presence of inhibitors, respectively.

Table 1. Molecular structure and abbreviation.

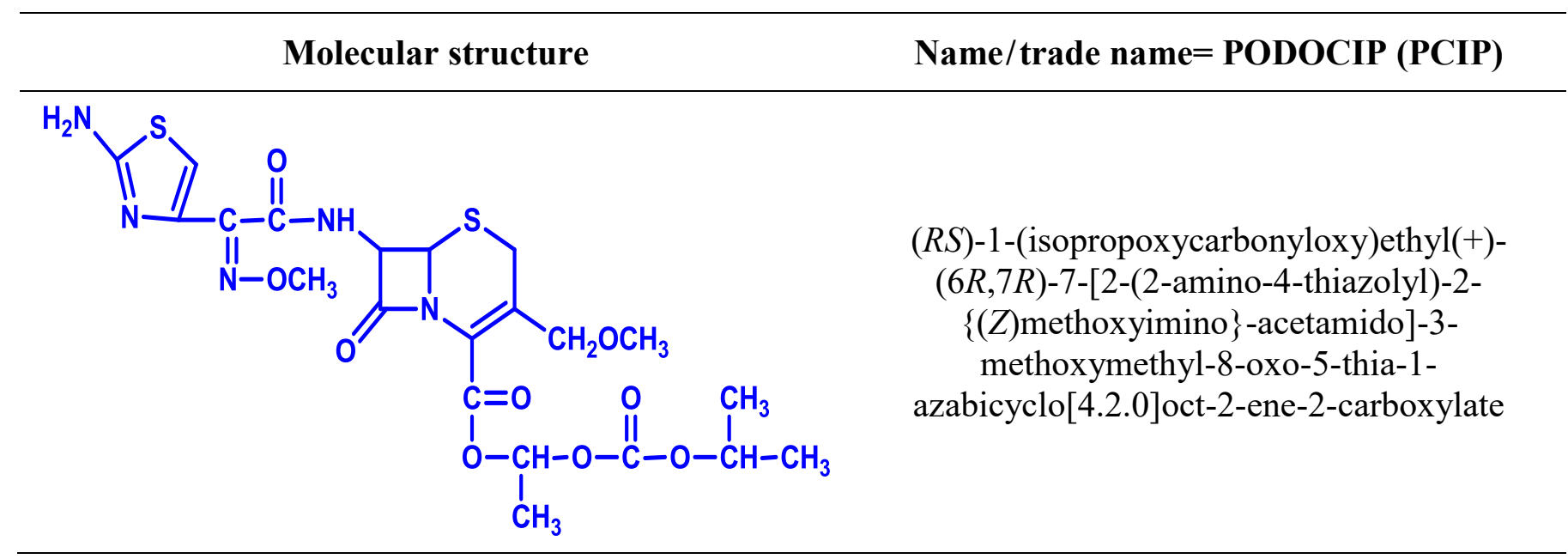

\subsection{Electrochemical measurements}

AC impedance (EIS) measurements and potentiodynamic polarization studies were carried out using a GAMRY PC14/300 electrochemical workstation based on ESA400. Gamry applications include EIS300 (for EIS measurements) and DC105 software (for corrosion) and Echem Analyst (version 5.50) software for data fitting. All electrochemical experiments were performed in a Gamry three electrode electrochemical cell under atmospheric conditions with a platinum counter electrode and a saturated calomel electrode (SCE) as the reference electrode. The carbon steel working electrode ( $7.5 \mathrm{~cm}$ long stem) with the exposed surface of $1.0 \mathrm{~cm}^{2}$, was immersed in the aggressive electrolyte solution with and without inhibitor, and the open circuit potential was measured after $30 \mathrm{~min}$. EIS measurements were performed at corrosion potentials, $E_{\text {corr, }}$ over a frequency range of $100 \mathrm{kHz}$ to $10 \mathrm{mHz}$ with an AC signal amplitude perturbation of $10 \mathrm{mV}$ peak to peak. Potentiodynamic polarization studies were performed with a scan rate of $1 \mathrm{mV} \mathrm{s}^{-1}$ in the 
potential range from $250 \mathrm{mV}$ below the corrosion potential to $250 \mathrm{mV}$ above the corrosion potential. All potentials were recorded with respect to the SCE.

\subsubsection{Surface analysis}

Surface analysis of carbon steel strip was carried out at an accelerating voltage of $5 \mathrm{kV}$ and $5 \mathrm{k} \times$ magnifications on a Ziess Evo 50XVP instrument. The carbon steel strips of size $2.5 \times 2 \times 0.025 \mathrm{~cm}$ were immersed in $1 \mathrm{M} \mathrm{HCl}$ in the absence and the presence of the inhibitor (PCIP) at optimum concentration $\left(100 \mathrm{mg} \mathrm{L}^{-1}\right)$ for $3 \mathrm{~h}$. After this, the sample was taken out, washed with distilled water, degreased with acetone and dried at the ambient temperature. For SEM study, the size of the sample was $1 \mathrm{~cm}^{2}$. The surface analysis through AFM was carried out using the NT-MDT multimode AFM, Russia, 111 controlled by Solver scanning probe microscope controller. The single beam cantilever with resonance frequency in the range of $240-255 \mathrm{kHz}$ in semi-contact mode having a corresponding spring constant of $11.5 \mathrm{~N} \mathrm{~m}^{-1}$ having NOVA program was used for image interpretation.

\section{Results and Discussion}

\subsection{Gravimetric measurements}

\subsubsection{Effect of inhibitor concentration}

The effect of inhibitor (PCIP) concentration shown in Figure 1(a) reveals that the corrosion inhibition efficiency increased on increasing the concentration of inhibitor. The obtained inhibition efficiency at optimum concentration $\left(100 \mathrm{mg} \mathrm{L}^{-1}\right)$ was $96.57 \%$.

\subsubsection{Effect of temperature}

The effect of temperature was determined at the temperature range $(308-338 \mathrm{~K})$ at optimum concentration $\left(100 \mathrm{mg} \mathrm{L}^{-1}\right)$ in absence and presence of inhibitor in $1 \mathrm{M} \mathrm{HCl}$ and shown in Figure 1(b). It can be observed that the inhibition efficiency decreases on increasing the temperature, which indicates desorption of inhibitor molecules from the carbon steel surface. At higher temperature, due to increase in desorption of inhibitor from metal surface, a greater surface area of carbon steel strip comes in contact of corrosion environment [22]. The temperature dependence of corrosion rates $\left(C_{R}\right)$ was estimated using Arrhenius equation.

The activation energy was calculated by,

$$
C_{\mathrm{R}}=A \exp \left(\frac{-E_{\mathrm{a}}}{R T}\right)
$$

Where $E_{\mathrm{a}}$ denotes activation energy, $R$ is the gas constant, $A$ is the pre-exponential factor. Arrhenius plots for the corrosion rate of carbon steel are shown in Figure 1c. The values of $E_{\mathrm{a}}$ for carbon steel in $1 \mathrm{M} \mathrm{HCl}$ in the absence and presence of inhibitors was calculated by 
linear regression between $\log \left(C_{\mathrm{R}}\right)$ and $1 / T$. Thus, the adsorbed inhibitor molecules prevent charge or mass transfer from the carbon steel surface.

\subsubsection{Adsorption examination}

Organic compounds show the inhibition property via adsorption on metal surface, and some adsorption isotherms (Frumkin, Langmuir, Temkin etc.) have been widely used to study the mechanism of corrosion inhibition. In this study, Langmuir adsorption isotherm which is a plot of $C / \theta$ against $C$ was fitted and is shown in Figure 1(d).

The adsorption examination was done by the help of Langmuir isotherm [23].

$$
\frac{C_{\mathrm{inh}}}{\theta}=\frac{1}{K_{\mathrm{ads}}}+C_{\mathrm{inh}}
$$

Where $\theta$ is the surface coverage, $\mathrm{C}$ is the inhibitor concentration, $K_{\mathrm{ads}}$ is the equilibrium constant of adsorption process. The equilibrium constant $K_{\text {ads }}$ is also related to the Gibbs free energy of adsorption reaction,

$$
K_{\text {ads }}=\frac{1}{C_{(\text {sol. })}} \exp \left(\frac{\Delta G_{\text {ads }}^{0}}{R T}\right)
$$

Where $R$ is the gas constant and $T$ is the absolute temperature. The value of 55.5 is the concentration of water in solution in $\mathrm{mol} \mathrm{L}^{-1}$ where $R$ is the gas constant and $\mathrm{T}$ is the absolute temperature. The values of $K_{\text {ads }}$ and $\Delta G_{\text {ads }}^{0}$ for different temperatures are listed in Table 2. The calculated value of $\Delta G_{\text {ads }}^{0}$ lies in between $-33.37 \mathrm{~kJ} / \mathrm{mol}$ to $39.16 \mathrm{~kJ} / \mathrm{mol}$ which indicates that the adsorption of the inhibitor on mild steel surface follows both physical and chemical modes [24].

Table 2. Thermodynamic parameters for the adsorption of PCIP on mild steel in $1 \mathrm{M} \mathrm{HCl}$ at different temperatures.

\begin{tabular}{ccc}
\hline Inhibitor & $\boldsymbol{K}_{\text {ads }}\left(\mathbf{1 0}^{\mathbf{3}} \mathbf{M}^{\mathbf{- 1}}\right)$ & $-\Delta G_{\text {ads }}^{0}\left(\mathbf{k J ~ m o l}^{\mathbf{1}}\right)$ \\
\hline 308 & 195.78 & -39.16 \\
318 & 96.14 & -34.87 \\
328 & 56.74 & -33.26 \\
338 & 25.86 & -33.37 \\
\hline
\end{tabular}



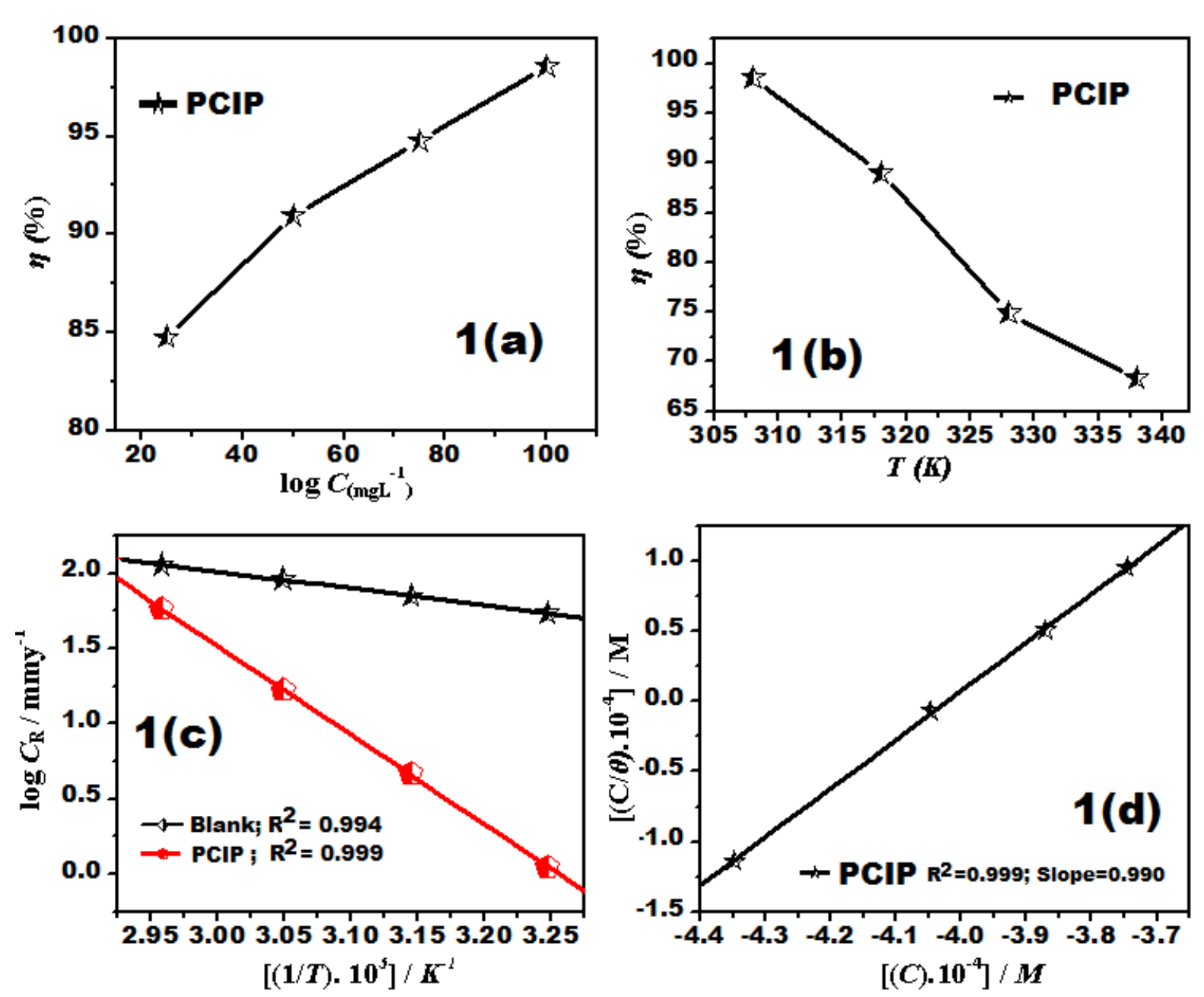

Figure 1. (a) Variation of the inhibition efficiency ( $\eta \%)$ with inhibitor concentration at $308 \mathrm{~K}$; (b) Variation of inhibition efficiency $(\eta \%)$ with solution temperature $(308-338 \mathrm{~K})$ at optimum concentration of inhibitor; (c) Arrhenius plots of the corrosion rate $\left(C_{R}\right)$ of mild steel in $1 \mathrm{M}$ $\mathrm{HCl}$ in the absence and presence of $100 \mathrm{mg} \mathrm{L}^{-1}$ of PCIP; (d) Langmuir isotherm plot for adsorption of PCIP on mild steel surface in $1 \mathrm{M} \mathrm{HCl}$.

\subsection{Electrochemical measurements}

\subsubsection{Electrochemical Impedance Spectroscopy}

Figure 2(a) shows impedance results in the form of Nyquist plots in the absence and presence of PCIP at different concentrations $\left(25 \mathrm{mg} \mathrm{L}^{-1}\right.$ to $\left.100 \mathrm{mg} \mathrm{L}^{-1}\right)$. This technique is usually used to explain the adsorption mechanism of inhibitor molecules on the carbon steel surface. An increase in the diameter of the capacitive loops with increase in the concentration of the PCIP suggests that the PCIP acts as an efficient corrosion inhibitor for carbon steel. The inhibitor molecules get adsorbed on the carbon steel surface and block the active sites available for corrosion thereby causing an increase in the $R_{\mathrm{p}}$ values which is associated with the mitigation of corrosion. The inhibition efficiency can be calculated as follows, 


$$
\eta \%=\frac{R_{\mathrm{p}(\mathrm{inh})}-R_{\mathrm{p}}}{R_{\mathrm{p}(\mathrm{inh})}} \times 100
$$

Where, $R_{\mathrm{p}(\mathrm{inh})}$ and $R_{\mathrm{p}}$ are the values of polarization resistance in the absence and the presence of inhibitor in $1 \mathrm{M} \mathrm{HCl}$ respectively. The inhibition efficiency obtained in the presence of PCIP at $100 \mathrm{mg} \mathrm{L}^{-1}$ is $97.93 \%$. All the impedance parameters were calculated with the application of the equivalent circuit model given in Figure 2(b). The circuit consists of $R_{\mathrm{S}}$ (the resistance of solution between working electrode and counter electrode), and $R_{\mathrm{p}}$ polarization resistance. The double layer usually behaves as a constant phase element (CPE) rather than pure capacitor. The CPE is substituted for the capacitor to fit the semicircle more accurately. The impedance of CPE is expressed as [25]:

$$
Z_{\mathrm{CPE}}=Y_{0}^{-1}(j \omega)^{-n}
$$

Here, $Y_{0}$ is the amplitude comparable to a capacitance, $j$ is the square root of $-1, \omega$ is angular frequency $\left(\omega=2 \pi f_{\max }\right)$ at which the imaginary part of the impedance $\left(-Z_{\text {im }}\right)$ is maximal and $f_{\max }$ is $\mathrm{AC}$ frequency at maximum, $n$ is the phase shift, which can be used as a gauge of the heterogeneity or roughness of the carbon steel surface [26-28]. The decrease in double layer capacitance $\left(C_{\mathrm{dl}}\right)$ value (Table 3$)$ in presence of PCIP as compared to that in its absence can be attributed to a decrease in the dielectric constant or increase in the thickness of the electrical double layer, which suggests the adsorption of PCIP at the metal/solution interface [29]. The $C_{\mathrm{d} 1}$ can be calculated as follows:

$$
C_{\mathrm{dl}}=\frac{Y \omega^{n-1}}{\sin (n(\pi / 2))}
$$

where $n$ is the phase shift, which can be used as a gauge of the heterogeneity or roughness of the carbon steel surface. The addition of inhibitor to the corrosive solution decreases the double layer capacitance $\left(C_{\mathrm{dl}}\right)$. This decrease in $C_{\mathrm{dl}}$ value is due to the formation of a protective layer on the electrode surface [30].

The Bode impedance magnitude and phase angle plots recorded for carbon steel electrode immersed in $1 \mathrm{M} \mathrm{HCl}$ in the absence and presence of different concentrations of inhibitor are given in Figure 2(c). The impedance plots at higher frequency limit $(100 \mathrm{kHz})$ correspond to the ohmic resistance of the films of corrosion product and the solution between the working electrode and the reference electrode. At high frequency, the values of $\log |Z|$ and phase angle fall to zero. This indicates the resistive behavior of carbon steel electrode which corresponds to solution resistance enclosed between the reference and the working electrodes [31]. It is observed that in the intermediate frequency region, a linear relationship between $\log |Z| v s . \log f$ with a slope approaching towards -1 and the phase angle approaching towards $-80^{\circ}$ can be observed (Table 3 ). This indicates the capacitive behavior at intermediate frequencies. 

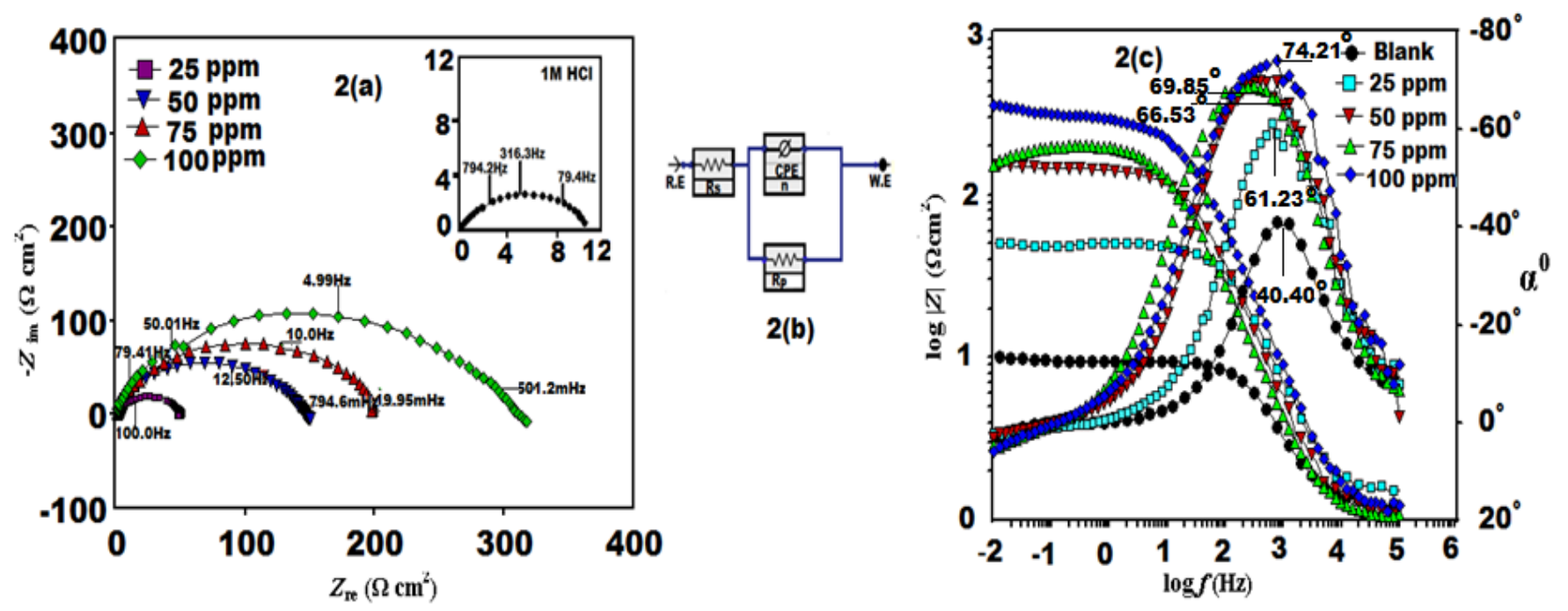

Figure 2. (a) Nyquist plots for carbon steel surface in $1 \mathrm{M} \mathrm{HCl}$ in the absence (inset) and presence of different concentrations of PCIP at $308 \mathrm{~K}$; (b) Equivalent circuit model used to fit the EIS data; (c) Bode $(\log f$ vs $\log |\mathrm{Z}|)$ and phase angle $(\log f v s . \alpha)$ plots of impedance spectra for carbon steel in $1 \mathrm{M} \mathrm{HCl}$ in the absence and presence of different concentrations of PCIP at $308 \mathrm{~K}$.

Table 3. Electrochemical impedance parameters for carbon steel in $1 \mathrm{M} \mathrm{HCl}$ solution in the absence and presence of different concentration of PCIP at $308 \mathrm{~K}$.

\begin{tabular}{|c|c|c|c|c|c|c|}
\hline $\begin{array}{l}\text { PCIP } C_{\text {inh }} \\
\left(\mathrm{mg} \mathrm{L}^{-1}\right)\end{array}$ & $\begin{array}{c}R_{\mathrm{s}} \\
(\Omega)\end{array}$ & $\begin{array}{c}R_{p} \\
\left(\Omega \mathrm{cm}^{2}\right)\end{array}$ & $n$ & $\begin{array}{c}Y_{0} \\
\left(\mu \mathrm{F} \mathrm{cm}^{-2}\right)\end{array}$ & $\begin{array}{c}C_{\mathrm{dl}} \\
\left(\mu \mathrm{F} \mathrm{cm}^{-2}\right)\end{array}$ & $\begin{array}{c}\eta \\
(\%)\end{array}$ \\
\hline Blank & 1.02 & 7.44 & 0.798 & 481.2 & 137.9 & - \\
\hline 25 & 1.463 & 48.16 & 0.867 & 92.65 & 53.01 & 81.88 \\
\hline 50 & 1.071 & 143.5 & 0.87 & 78.65 & 44.19 & 94.06 \\
\hline 75 & 1.03 & 187.6 & 0.849 & 55.98 & 30.82 & 95.46 \\
\hline 100 & 1.15 & 302.4 & 0.872 & 39.41 & 21.05 & 97.93 \\
\hline
\end{tabular}

\subsubsection{Potentiodynamic polarization}

The potentiodynamic polarization curves of PCIP at $308 \mathrm{~K}$ at different concentrations are shown in Figure 3. Different potentiodynamic polarization parameters including corrosion potential $\left(E_{\text {corr }}\right)$, anodic Tafel slopes $\left(\beta_{\mathrm{a}}\right)$, cathodic Tafel slopes $\left(\beta_{\mathrm{c}}\right)$ and corrosion current density $\left(i_{\text {corr }}\right)$ were obtained by extrapolating the polarization curves. Inhibition efficiency $(\eta \%)$, calculated using equation 10 , is also listed in Table 4 :

$$
\eta \%=\left(1-\frac{i_{\text {corr (i) }}}{i_{\text {corr }}}\right) \times 100
$$


where, $i_{\text {corr }}$ and $i_{\text {corr(i) }}$ are the uninhibited and inhibited corrosion current densities, respectively. The values in Table 4 reveal that there is a decrease in the corrosion current density in the presence of PCIP, which creates a barrier between carbon steel and corrosive medium during electrochemical process indicating the formation of a protective film on the carbon steel surface. Also, with the addition of PCIP, both $\beta_{\mathrm{a}}$ and $\beta_{\mathrm{c}}$ values decreased with respect to blank. Tafel plot indicates that the PCIP compounds affect the kinetics of Fe dissolution and hydrogen evolution reactions. PCIP acts as a mixed type corrosion inhibitor by affecting both cathodic and anodic reactions [32].

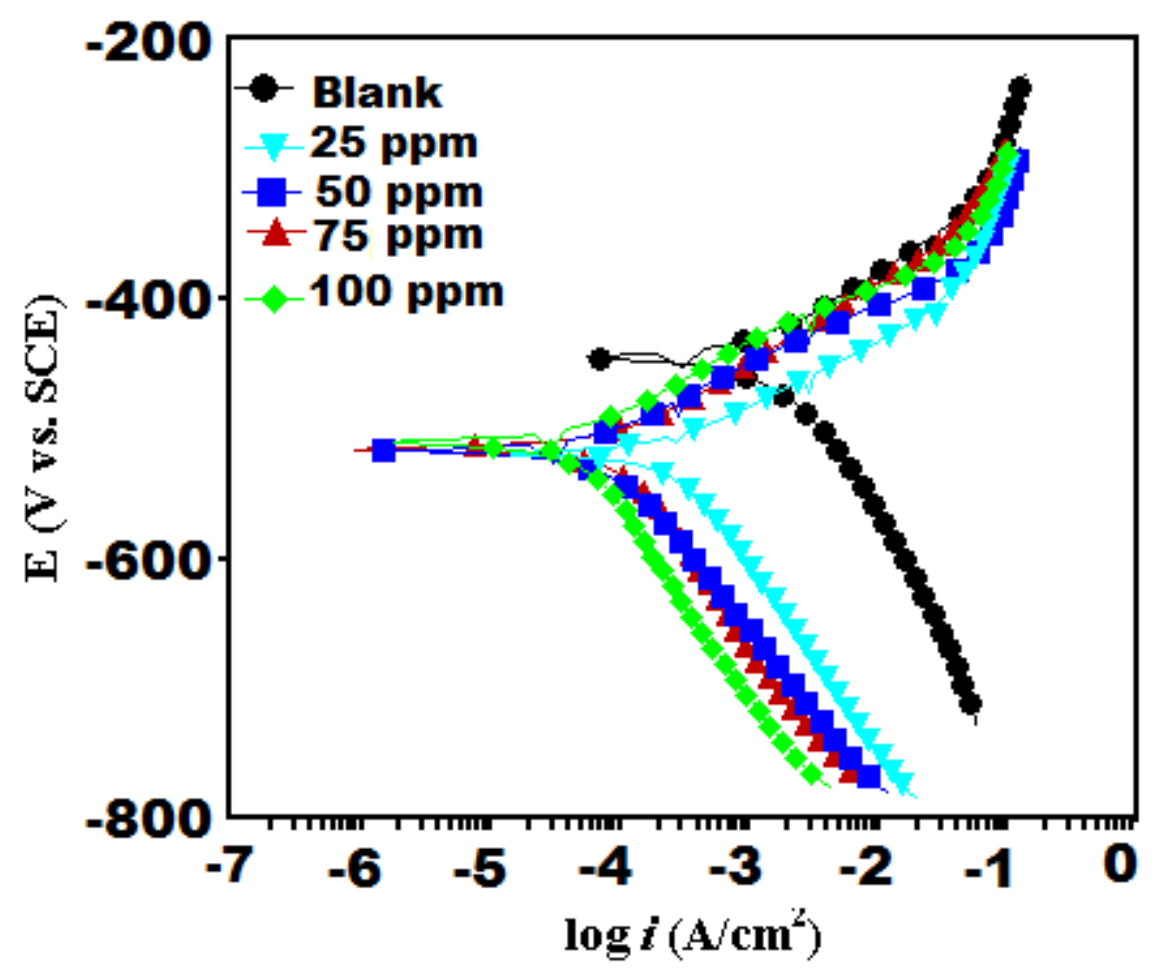

Figure 3. Polarization curves for carbon steel in the absence and presence of different concentrations of PCIP.

Table 4. Potentiodynamic polarization parameters for carbon steel in $1 \mathrm{M} \mathrm{HCl}$ solution in the absence and presence of different concentrations of PCIP at $308 \mathrm{~K}$.

\begin{tabular}{|c|c|c|c|c|c|}
\hline $\begin{array}{c}\text { PCIP } C_{\text {inh }} \\
\left(\mathrm{mg} \mathrm{L} \mathrm{L}^{-1}\right)\end{array}$ & $\begin{array}{c}E_{\text {corr }} \\
(\mathbf{m V} / \mathbf{S C E})\end{array}$ & $\begin{array}{c}i_{\text {corr }} \\
\left(\mu \mathrm{A} / \mathbf{c m}^{2}\right)\end{array}$ & $\begin{array}{c}\boldsymbol{\beta}_{\mathbf{a}} \\
\text { (mV/dec) }\end{array}$ & $\begin{array}{c}-\boldsymbol{\beta}_{\mathrm{c}} \\
(\mathrm{mV} / \mathrm{dec})\end{array}$ & $\begin{array}{c}\eta \\
(\%)\end{array}$ \\
\hline Blank & -445 & 892 & 74.6 & 123.9 & - \\
\hline 25 & -515 & 86.3 & 51 & 91.9 & 90.32 \\
\hline 50 & -517 & 68.65 & 54.6 & 106.3 & 92.30 \\
\hline 75 & -518 & 48.6 & 54.9 & 143.9 & 94.55 \\
\hline 100 & -510 & 21.8 & 56.8 & 145.2 & 97.55 \\
\hline
\end{tabular}




\subsection{Surface analysis}

The SEM images of inhibited and uninhibited carbon steel specimens after $3 \mathrm{~h}$ immersion time are shown in Figure $4(a, b)$. It can be seen from the Figure $4 a$ that the carbon steel specimen of uninhibited sample is highly damaged due to free acid corrosion. Moreover, the SEM image of the metallic specimen in the presence of PCIP is smoother than in the absence of PCIP. The AFM micrographs of carbon steel specimens in the absence and presence of optimum concentrations of PCIP are shown in Figure 4(c,d). The micrograph of the carbon steel surface shows a surface roughness of $250 \mu \mathrm{m}$ in the absence of PCIP and $80 \mu \mathrm{m}$ in the presence of PCIP. The results of SEM and AFM further corroborate the formation of protective film on metal surface.
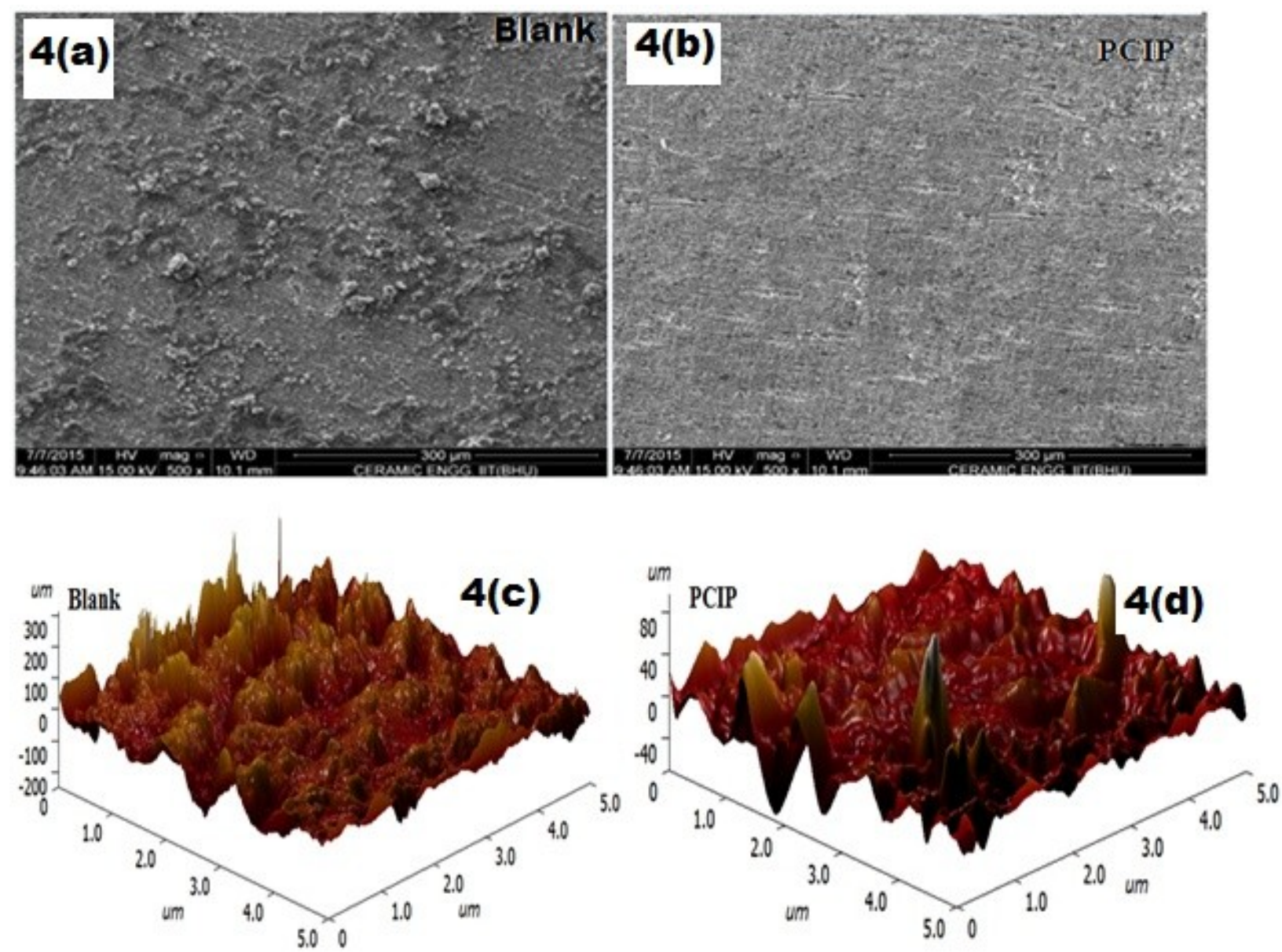

Figure 4. SEM micrographs of carbon steel surfaces: (a) blank, (b) PCIP; AFM micrographs: (c) blank, (d) PCIP.

A comparative chart of the corrosion inhibition performance of some of the earlier reported expired drugs along with that of the PCIP is shown in Table 5. It can be observed from the Table that PCIP shows significant corrosion inhibition behavior compared to other expired drugs. Therefore, it can be inferred that PCIP can be utilized for the 
application of corrosion inhibition with promising results. It is thus, obvious from the present study that the use of expired drugs is a significantly cost effective means to control corrosion. Furthermore, this study proposes a greener alternative to otherwise costly and cumbersome disposal and degradation methodology of expired drugs which present a major source of environmental nuisance.

Table 5. List of different expired drugs and their inhibition efficiency in $1 \mathrm{M} \mathrm{HCl}$ on mild steel.

\begin{tabular}{|c|c|c|c|c|}
\hline Drug & Test medium & Metallic surface & $\eta \%$ & Reference \\
\hline Carbamazepine & $0.1 \mathrm{M} \mathrm{H}_{2} \mathrm{SO}_{4}$ & Carbon steel & 90 & 33 \\
\hline Paracetamol & $\begin{array}{c}0.25 \mathrm{M} \text { acetic acid - } \\
0.25 \mathrm{M} \text { sodium } \\
\text { acetate buffer }\end{array}$ & Carbon steel & 85 & 33 \\
\hline Voltaren & $1 \mathrm{M} \mathrm{HCl}$ & Aluminium & 89.7 & 34 \\
\hline 1-Phenytoin & $1 \mathrm{M} \mathrm{HCl}$ & Carbon steel & 79.1 & 35 \\
\hline Amlodipine Besylate & $1 \mathrm{M} \mathrm{HCl}$ & Low Carbon steel & 94.3 & 36 \\
\hline Asthalin & $1 \mathrm{M} \mathrm{HCl}$ & Mild steel & 94.76 & 37 \\
\hline Ranitidine & $1 \mathrm{M} \mathrm{HCl}$ & Mild steel & 90.0 & 38 \\
\hline Amlodipine Besylate & $1 \mathrm{M} \mathrm{HCl}$ & Low Carbon steel & 83.5 & 39 \\
\hline Lupicof & $1 \mathrm{M} \mathrm{HCl}$ & Mild steel & 70.86 & 40 \\
\hline $\begin{array}{l}\text { 2-(2,6-dichloranilino)- } \\
\text { phenylacetic acid }\end{array}$ & $1 \mathrm{M} \mathrm{HCl}$ & Mild steel & 87.5 & 41 \\
\hline Lumerax-80 & $1 \mathrm{M} \mathrm{HCl}$ & Mild steel & 95.30 & 31 \\
\hline PCIP & $1 \mathrm{M} \mathrm{HCl}$ & Mild steel & 97.55 & Present work \\
\hline
\end{tabular}

\section{Conclusion}

The following conclusions can be drawn from the present study:

(1) The results showed that inhibitor Podocip (PCIP) has excellent inhibition efficiency for the corrosion of carbon steel in $1 \mathrm{M} \mathrm{HCl}$.

(2) The potentiodynamic polarization curves indicated that PCIP acts as a mixed type corrosion inhibitor.

(3) PCIP molecules follow Langmuir adsorption isotherm for the adsorption on metal surface in $1 \mathrm{M} \mathrm{HCl}$ solution.

(4) The impedance results indicate that the values of polarization resistance increased and double layer capacitance decreased. This result can be attributed to an increase in the thickness of the electrical double layer.

(5) The formation of protective inhibitor film was confirmed by SEM and AFM methods. 


\section{Acknowledgments}

Parul Dohare gratefully acknowledges Ministry of Human Resource Development (MHRD), New Delhi, India for the financial assistance and facilitation of this study.

\section{REFERENCES}

1. M. Behpour, S.M. Ghoreishi, N. Soltani, M. Salavati-Niasari, M. Hamadanian and A. Gandomi, Corros. Sci., 2008, 50, 2172.

2. P. Singh, E.E. Ebenso, L.O. Olasunkanmi, I.B. Obot and M.A. Quraishi, J. Phys. Chem. C, 2016, 120, 3408.

3. A.S. Fouda and A.S. Ellithy, Corros. Sci., 2009, 51, 868.

4. N. Esmaeili, J. Neshati and I. Yavari, J. Ind. Eng. Chem., 2015, 22, 159.

5. M. Faustin, A. Maciuk, P. Salvin, C. Roos and M. Lebrini, Corros. Sci., 2015, 92, 287.

6. E.A. Noor and A.H. Al-Moubaraki, Int. J. Electrochem. Sci., 2008, 3, 806.

7. M.H. Abd El-Lateef, Corros. Sci., 2015, 92, 104.

8. A. Peter and S.K. Sharma, Int. J. Corros. Scale Inhib., 2017, 6, no. 2, 112. doi: 10.17675/2305-6894-2017-6-2-2

9. R.S. Abdel Hameed and A.H. Shamroukh, Int. J. Corros. Scale Inhib., 2017, 6, no. 3, 333. doi: $10.17675 / 2305-6894-2017-6-3-8$

10. I.B. Obot, E.E. Ebenso and M. Kabanda, J. Environ. Chem. Eng., 2013, 1, 431.

11. S.K. Shukla, A.K. Singh, I. Ahamad and M.A. Quraishi, Mater. Lett., 2009, 63, 819.

12. S.K. Shukla and M.A. Quraishi, Corros. Sci., 2009, 51, 1007.

13. I. Ahamad, R. Prasad and M.A. Quraishi, J. Solid State Electrochem., 2010, 14, 2095.

14. S.K. Shukla and M.A. Quraishi, Mater. Chem. Phys., 2010, 120, 142.

15. A.K. Singh and M.A. Quraishi, Corros. Sci., 2010, 52, 152.

16. I. Ahamad, R. Prasad and M.A. Quraishi, Corros. Sci., 2010, 52, 651.

17. I. Ahamad, R. Prasad and M.A. Quraishi, Corros. Sci., 2010, 52, 3033.

18. P.M. Dasami, K. Parameswari and S. Chitra, Measurement, 2015, 69, 195.

19. N.A. Negm, E.A. Badr, I.A. Aiad, M.F. Zaki and M.M. Said, Corros. Sci., 2012, 65, 77.

20. ASTM, G 31-72, American Society for Testing and Materials, Philadelphia, PA, 1990.

21. N. Chaubey, D.K. Yadav, V.K. Singh and M.A. Quraishi, Ain Shams Eng. J., 2017, 88, 673.

22. P. Dohare, K.R. Ansari, M.A. Quraishi and I.B. Obot, J. Ind. Eng. Chem., 2017, 52, 197.

23. S. Ghareba and S. Omanovic, Corros. Sci., 2010, 52, 2104.

24. R. Solmaz, Corros. Sci., 2014, 81, 75.

25. R. Solmaz, Corros. Sci., 2014, 79, 169.

26. K. Hu, J. Zhuang, C. Zheng, Z. Ma, L. Yan, H. Gu, X. Zeng and J. Ding, J. Mol. Liq., 2016, 222, 109.

27. S. John, M. Kuruvilla and A. Joseph, RSC Adv., 2013, 3, 8929. 
28. D.T. Daoud, T. Douadi, S. Issaadi and S. Chafaa, Corros. Sci., 2014, 79, 50.

29. F. Touhami, A. Aouniti, Y. Abed, B. Hammouti, S. Kertit, A. Ramdani and K. Elkacemi, Corros. Sci., 2000, 42, 929.

30. A. Ehsani, M.G. Mahjani, R. Moshrefi, H. Mostaanzadeha and J.S. Shayehb, RSC Adv., 2014, 4, 20031.

31. P. Dohare, D.S. Chauhan, B. Hammouti and M.A. Quraishi, Anal. Bioanal. Electrochem., 2017, 9, 762.

32. I.B. Obot and Z.M. Gasem, Corros. Sci., 2014, 83, 359.

33. N. Vaszilcsin, V. Ordodi and A. Borza, Int. J. Pharm., 2012, 431, 241.

34. R.S.A. Hameed, E.A. Ismail, A.H. Abu-Nawwas and H.I. AL-Shafey, Int. J. Electrochem. Sci., 2015, 10, 2098.

34. H.I. AL-Shafey, R.S.A. Hameed, F.A. Ali, A.A.S. Aboul-Magd and M. Salah, Int. J. Pharm. Sci. Rev. Res., 2014, 27, 146.

36. A.S. Fouda, M.S. Motawee, H.S. Megahid and H.A.A. Mageed, Ind. J. Chem. Phram. Sci., 2015, 3, 1808.

37. P. Geethamani and P.K. Kasturi, J. Taiwan Inst. Chem. Eng., 2016, 63, 490.

38. R.S.A. Hameed, Port. Electrochim. Acta, 2011, 29, 273.

39. A.S. Fouda, W.M. Mahmoud and H.A.A. Mageed, J. Bio. Tribo. Corros., 2016, $2,7$.

40. P. Geethamani, P.K. Kasturi and S. Aejitha, Elixir Corros. Dye., 2014, 76, 28406.

41. R.S.A. Hameed, H.I. Al-Shafey and A.H. Abu-Nawwas, Int. J. Electrochem. Sci., 2014, 9, 6006 . 